\title{
Cidades, portos e cidades portuárias na era da integração produtiva*
}

\author{
Frédéric Monié** \\ Soraía Maria do S. C. Vidal***
}

S UMÁRIO: 1. Introdução; 2 . As três grandes fases do processo de globalização e a evolução do papel dos portos; 3 . As cidades portuárias na economia de circulação; 4. Alguns desafios para as políticas e gestão portuárias; 5. Considerações finais: inventar uma nova cultura portuária.

SUMMARY: 1. Introduction; 2. The three main stages of the globalization process and the evolution of the role of ports; 3. Port cities in the circulation economy; 4. Challenges for port management and policies; 5 . Final remarks: inventing a new port culture.

Palavras-chave: porto; cidade; território; globalização.

KEY WORDS: port; city; territory; globalization.

Este artigo discute a evolução das relações cidades/portos e os desafios impostos na era da globalização. A reorganização dos espaços produtivos e o surgimento de dinâmicas comerciais específicas incluíram um conjunto de mudanças na estrutura mundial dos portos. Dessa forma, a evolução do transporte marítimo sempre esteve associada à agilidade, traduzida pelo aumento da capacidade dos navios, por ganhos em velocidade e por uma diminuição significativa do custo do frete, contribuindo para o encurta-

* Artigo recebido em dez. 2005 e aceito em ago. 2006.

** Doutor em geografia pela Universidade de Paris III. Professor do Departamento de Geografia da UFRJ e do Laboratório de Gestão do Território, Programa de Pós-Graduação em Geografia. Endereço: Caixa Postal 68.537 - Ilha do Fundão - CEP 21941-972, Rio de Janeiro, RJ, Brasil. E-mail: fmonie@uol.com.br.

*** Doutora em ciências sociais pela Pontifícia Universidade Católica de São Paulo. Professora assistente do Programa de Pós-Graduação em Gestão de Negócios da Universidade Católica de Santos (Unisantos). Endereço: Rua Carvalho de Mendonça, 144 - Vila Mathias - CEP 11070-906, Santos, SP, Brasil. E-mail: soraiavidal@unisantos.br. 
mento relativo das distâncias para os homens, as mercadorias e as informações. A partir dos anos 1990, com a intensificação do processo de globalização, caracterizado pela crescente integração das esferas da produção, do consumo e da circulação em todas as escalas geográficas, novas demandas foram colocadas sobre os portos. No caso do Brasil, a ausência de uma política portuária nacional conferiu às iniciativas, federais ou locais, um caráter fragmentado. Apesar dos resultados operacionais positivos, as inovações institucionais, mais especificamente em termos de governança portuária, são escassas. Criar uma nova cultura portuária é um desafio central para a definição de políticas públicas inovadoras e a transformação dos portos em vetores de desenvolvimento. São esses os pressupostos que conduziram este artigo, resultado de pesquisas temáticas acerca de portos e territórios.

\section{Cities, ports, and port cities in the integrated production era}

This article discusses the evolution of city/port relations and the challenges imposed by globalization. The worldwide reorganization of production spaces and the appearance of specific commercial dynamics have included changes in port structures throughout the world. Therefore, progress in maritime transportation has always been associated to agility, translated by larger ship capacity, gains in speed, and a significant reduction of freight costs, contributing to the relative shortening of distances for people, merchandise and information. Since 1990, with the intensification of the globalization process, characterized by the growing integration of production, consumption and circulation spheres in all geographic scales, the ports had to answer to new demands. In the case of Brazil, the absence of a national port policy gave a fragmented character to federal and local initiatives. Despite the positive operational results, institutional innovations, more specifically in terms of port governance, are sparse. The creation of a new port culture is a central challenge for defining innovative public policies and transforming ports in development vectors. Theses are the presuppositions of this article, which is a result of thematic surveys on ports and territory.

\section{Introdução}

A reorganização mundial dos espaços produtivos e o surgimento de dinâmicas comerciais específicas incluíram também um conjunto de mudanças na estrutura mundial dos portos: novos métodos de movimentação de cargas, equipamentos com sofisticação tecnológica, mão-de-obra especializada e agilidade. E mais os avanços da engenharia naval e a construção de novos tipos de navios mercantes, como os Ro-Ro para o transporte de veículos. No entanto, atribui-se a maior transformação do setor aos navios conteineiros especial- 
mente projetados para a maximização do transporte de contêineres, ícone das transformações mundiais no transporte e manuseio de cargas. A eficiência e a dinâmica de um porto não se limitam apenas às instalações e à capacidade dos navios, mas principalmente ao seu entorno, dadas as atividades produtivas que fazem uso dos seus serviços, ou seja, sua hinterlândia. Reafirma-se que a dinâmica portuária e as mudanças nos métodos das operações portuárias sempre estiveram associadas à reorganização mundial dos espaços produtivos e ao surgimento de dinâmicas comerciais específicas. Com a globalização, novas demandas foram colocadas sobre os portos, o que resultou em mudanças no sistema portuário mundial e nas cidades com portos. Em relação ao porto, destaca-se que o mesmo não pode ser pensado apenas do ponto de vista técnico e operacional. Ele não é apenas um corredor, ele é mais: um instrumento a serviço de um projeto de desenvolvimento.

Este artigo aceita como pressuposto básico as interações entre porto e processos produtivos. Ao mesmo tempo, ressalta um novo cenário global favorável à aproximação porto-cidade, bem como a necessidade de um projeto democrático envolvendo forças públicas e privadas na construção de comunidades portuárias, a exemplo do que já ocorre no norte da Europa (Antuérpia e Havreés).

Consideradas as diversas características do mundo globalizado, destaca-se a prática que prioriza a agilidade nas conexões que transportam bens ou serviços, tangíveis e/ou intangíveis, e também uma maior valorização das potencialidades locais, que deveriam interagir com a dinâmica do comércio local ou global sob a ótica da sustentabilidade. Com as alternativas de transportes, a intermodalidade que reúne os processos na cadeia de produção global impulsiona o transporte marítimo e solicita expansão das escalas e rotas marítimas mundiais e o aumento da capacidade física e operacional dos navios. Nessa perspectiva, a articulação e conexão modal são fundamentais ao trânsito mercantil, no sentido de assegurar o processo sistêmico de integração e circulação de mercadorias, e tal processo nem sempre resultou em uma melhor integração porto-cidade.

Particularmente no caso dos portos e cidades, estudos de autores como Ferreira (1997) e Sales (1999) indicam um processo de afastamento contínuo entre cidades e portos, já a partir dos anos 1950, sempre associado à eficiência dos fluxos. Desde a década de 1950 (EUA) e décadas de 1960 e 1970 (na maioria dos países da Europa ocidental), cidades e portos apresentam processos de desorganização e redefinição de funções decorrentes, entre outros aspectos, dos avanços da engenharia naval, do aumento da capacidade dos navios, da introdução de novos métodos de manuseio de cargas e também necessidades de mercado. $\mathrm{O}$ tema além de ser relativamente novo, origi- 
nou-se da necessidade de ganhos de produtividade na movimentação das mercadorias, e as mudanças nem sempre foram imunes aos conflitos. Assim, a relação porto-cidade somente é compreendida quando refletida nas seqüências das transformações globais (sociais, políticas e econômicas), bem como as interfaces necessárias para um porto global: sistemas de trocas mundiais, sistemas econômicos, dinâmicas econômicas locais e dinâmicas urbanas específicas.

Os aspectos até aqui abordados possibilitam a formulação das seguintes questões: na cidade portuária estão reunidas as condições políticas e consensos entre os diversos agentes sociais e privados envolvidos na gestão portuária? Quais são os elementos necessários à formulação de uma política portuária que integre o porto a um projeto de desenvolvimento? Quais são os elementos característicos das cidades-eixo? Esta última denominação, presente nos escritos de autores como Baudouin (1999) e Seassaro (1999), diz respeito às cidades portuárias com papel econômico central regional. Para tanto, são necessários investimentos estruturais e funcionais que perpassam os limites do território portuário. Nessa perspectiva, o papel integrador do espaço produtivo, das cidades portuárias, seria fortalecido. $\mathrm{O}$ alargamento da cadeia produtiva impõe às cidades portuárias enfrentamentos complexos que vão desde questões estruturais e instrumentais do próprio cais, até o embate com questões socioeconômicas e ambientais, antes tratadas isoladamente e desconsideradas da cadeia produtiva, bem como a definição de políticas e instrumentos necessários à gestão do porto e da cidade. Nesse caso, parece oportuno discutir e recuperar aspectos da cultura portuária das cidades com portos. Como conciliar interesses por vezes tão distintos, ou ainda, como integrar práticas diversas? Essas questões serão o fio condutor da análise.

As informações que propiciaram a elaboração do artigo resultaram de pesquisas direcionadas ao entendimento da inserção territorial dos portos, bem como à qualificação dos processos de gestão portuária. $\mathrm{O}$ artigo, além desta introdução, está estruturado em quatro seções: a primeira se refere às fases distintas do processo de mundialização da economia; a segunda destaca e reafirma o papel das cidades portuárias em uma economia de circulação; a terceira recupera elementos necessários à definição de uma política portuária; e as considerações finais são direcionadas à definição de uma cultura das cidades portuárias.

\section{As três grandes fases do processo de globalização e a evolução do papel dos portos}

Nos meados do século XIX, o processo de difusão da Revolução Industrial, da Inglaterra para o continente europeu, abriu uma nova era no processo histórico de expansão do capitalismo, e foi considerada por alguns autores a primei- 
ra mundialização. Politicamente, esse período se caracterizou pela afirmação dos Estados-nação, que formaram progressivamente um sistema interestatal internacional. No plano comercial, a época foi caracterizada por um grande dinamismo das trocas internacionais em função da especialização crescente das economias nacionais que valorizavam cada vez mais suas vantagens relativas na produção de determinados bens. A Divisão Internacional do Trabalho (DIT) deixou bastante claro essa especialização produtiva e comercial à medida que os países se concentravam na exportação de um elenco bastante limitado de bens. Nos países centrais esses bens eram, em geral, manufaturados - os famosos artigos de Paris franceses, o têxtil suíço, os produtos químicos da Alemanha. Nos países periféricos, a especialização em produtos primários ou pouco processados - borracha na Indochina, amendoim no Senegal ou café no Brasil — traduziam uma inserção desigual no sistema mundial em via de consolidação. Os fluxos comerciais entre as nações cresceram muito. Em 1880, o comércio era responsável por 18\% do PIB mundial contra $9 \%$ em 1850. Esse processo foi possibilitado pela diminuição das barreiras ao livre-comércio e pelo progresso sem precedentes dos transportes na segunda metade do século XIX. O transporte marítimo sofreu uma verdadeira revolução, que se traduziu concretamente pelo aumento da capacidade dos navios, por ganhos em velocidade e por uma diminuição significativa do custo do frete, contribuindo para o encurtamento relativo das distâncias para os homens, as mercadorias e as informações (Harvey, 1989). Paralelamente, os portos das cidades inseridas no mundo industrial moderno foram reestruturados para acompanhar o movimento de modernização do transporte marítimo. No Brasil, a construção de portos modernos em Santos e no Rio de Janeiro ilustra claramente esse fenômeno. Os investimentos realizados em infra-estrutura e equipamentos portuários se inscreveram numa dinâmica de modernização sistemática dos instrumentos técnicos suscetíveis de valorizar as vantagens comparativas da economia brasileira por intermédio da facilitação das operações de drenagem do interior para o litoral.

Nas décadas seguintes, entretanto, guerras, conflitos, crises financeiras e recessão econômica resultaram na desaceleração da dinâmica do processo histórico de globalização. Os governos dos países centrais adotaram medidas que restringiram os fluxos de pessoas e de mercadorias. Medidas protecionistas de todos os tipos - alfandegárias, fiscais, sanitárias — pretendiam proteger as economias que passaram a crescer e se desenvolverem dentro dos limites do território nacional. Em alguns países da periferia, como o Brasil, a estratégia de proteção do mercado interno associado a políticas de substituição das importações permitiu a transição do modelo primário-exportador para um modelo mais urbano-industrial. Nos países centrais, as empresas se 
beneficiaram das proteções erguidas pelos governos para se consolidarem internamente por meio da inovação tecnológica e de investimentos na capacidade de produção que permitiram eliminar os concorrentes menos competitivos. No que diz respeito aos sistemas de circulação, eles são também bastante centrados no território nacional. Grandes eixos de escoamento têm por função o transporte de grandes volumes de produtos padronizados e já valorizados entre unidades que produzem em larga escala e mercados que consomem em massa esses produtos. É oportuno ressaltar que à produção e ao consumo em massa corresponde uma circulação também em massa.

Nesses sistemas circulatórios os portos também apresentaram uma evolução radical pela perda, parcial ou total, de suas funções comerciais tradicionais que se traduziram, por exemplo, pela degradação das áreas portuárias, cuja representação é cada vez mais negativa na sociedade devido tanto à sua associação sistemática aos problemas de insegurança, prostituição, engarrafamentos ou poluição ambiental quanto a estigmas e preconceitos. Para que os portos, dentro da lógica dominante da competitividade, pudessem apresentar fatores de diferenciação em relação aos seus concorrentes, foram necessárias reformulações que objetivaram uma diminuição de custos operacionais, com ganhos de produtividade, e o processo de conteinerização, tido como fundamental para o alto investimento em equipamento fixo.

A importação de volumes crescentes de insumos por parte dos países industrializados ou em via de industrialização ampliou essa tendência. A necessidade de operar uma primeira transformação dos insumos atraíram alguns setores de base nos complexos portuários industriais que surgiram nas décadas de 1960 e 1970 na Itália, na França e no Japão. No Brasil, investimentos de setores industriais pesados - siderurgia, metalurgia, petroquímica ou química de segunda geração - transformaram em poucos anos a Baixada Santista em um dos maiores centros industriais do hemisfério Sul. No sentido interior-litoral, a industrialização do ABC paulista trouxe imperativos novos em termos de fluidez do escoamento dos bens destinados ao mercado nacional - via cabotagem - e ao mercado externo. A inserção de Santos e de outros portos nos circuitos da produção industrial transformou a cidade-porto em simples anexo ou prolongamento das linhas de montagem de tipo fordista (Cocco e Silva, 1999). O porto foi transformado em mero substrato físico que possibilitava um conjunto de operações industriais, de transporte e de distribuição. Em conseqüência disso, recursos foram aplicados na ampliação da capacidade operacional das instalações portuárias mesmo se, contraditoriamente, a baixa taxa de abertura da economia nacional limitasse os investimentos no setor, com conseqüente degradação rápida do equipamento portuário. 
Logo, a baixa competitividade dos portos brasileiros e os elevados custos operacionais foram identificados como impeditivos de uma melhor inserção comercial do país, no início dos anos 1990. O período também se caracterizou por um intenso processo de transformações econômicas, em nível mundial, num duplo processo de abertura comercial e de reestruturação produtiva, que posicionou os portos no centro de uma economia de fluxos cada vez mais dinâmica. Recolocando em pauta a temática da relação cidade-porto.

A partir do início da década de 1990, assistiu-se a uma intensificação do processo de globalização caracterizado pela crescente integração das esferas da produção, do consumo e da circulação em todas as escalas geográficas (Monié, 2003; Veltz, 2002). As empresas desenvolveram novas estratégias de expansão no intuito de reestabelecer suas margens de lucro, em um ambiente altamente competitivo. Passaram a ser práticas empresariais a busca de novos mercados por meio da inovação - sofisticação crescente dos bens, multiplicação das opções para cada bem - e da difusão mundial dos seus produtos, com destaque para os países emergentes da Ásia e da América Latina onde existiam nichos de consumo já consolidados. No entanto, a globalização não se limitou a uma intensificação e a uma mudança de escala das trocas comerciais, uma vez que, paralelamente, a reestruturação produtiva transformou o espaço econômico mundial, contribuindo também para conferir uma centralidade maior ao sistema marítimo portuário internacional no seio do espaço global dos fluxos (Castells, 1999). Podemos ressaltar uma primeira dinâmica que consistiu na relocalização das plantas fabris de alguns setores de baixo e médio conteúdos tecnológicos, rumo a regiões que ofereciam baixos custos de produção e acessibilidade ao espaço econômico da empresa.

A nova dinâmica econômica apontada pode ser interna, como observamos no Brasil com a desconcentração da indústria gaúcha de calçados para o sertão nordestino; ou externa, como ilustram os investimentos realizados na China nos setores de confecção, brinquedos, maquinário pesado etc. A generalização do outsourcing representa uma segunda dinâmica maior da reestruturação produtiva. As grandes empresas tendem, assim, a multilocalizar a produção e a montagem dos seus produtos, segundo estratégias de terceirização extremamente complexas e diversas. Formam-se redes de valor agregado (Veltz, 2002) que articulam alguns núcleos centrais - localizados nas grandes metrópoles dos países centrais e emergentes - e periferias múltiplas, onde as unidades são localizadas em função de sua capacidade de abastecer in time a rede em peças, componentes ou semimanufaturados, oferecendo bens de qualidade, custos de produção baixos e flexibilidade em face das oscilações da demanda. Enfim, a acessibilidade aos grandes dispositivos logísticos regionais e mundiais constitui outro fator de competitividade para os 
fornecedores que integram as redes produtivas multilocalizadas (Monié, 2003).

A multilocalização (distribuição e diversificação territorial das unidades produtivas) da produção só foi possível graças a grandes mudanças institucionais que viabilizaram a redução das barreiras do livre-comércio e a flexibilização das legislações trabalhistas que transformou radicalmente a relação capital/trabalho, característica do fordismo e de sua vertente desenvolvimentista na periferia. Ao mesmo tempo, as novas tecnologias da comunicação e da Informação (NTCI) e o progresso registrado no setor dos transportes foram fundamentais para propiciar uma maior diversidade de escolhas locacionais para as empresas.

Em um contexto caracterizado pela "reticularização" dos processos produtivos, a qualidade das interações torna-se fundamental da microescala das trocas imateriais entre trabalhadores dos circuitos superiores da economia metropolitana - pesquisa, inovação de process, concepção, design, marketing até a macroescala das rotas de transporte intercontinentais. Ou seja, a reestruturação produtiva inclui uma verdadeira explosão dos fluxos imateriais e materiais nas mais diversas escalas geográficas. A formação do espaço global de fluxos (Castells, 1999), combinado aos efeitos do ingresso do ex-mundo comunista na economia de mercado (URSS), a força dos processos de integração regional e a emergência de novas potências comerciais alimentam o dinamismo extraordinário do comércio internacional desde o início dos anos 1990.

\begin{tabular}{|lcccccc|}
\hline \multicolumn{7}{|c|}{ Evolução do volume e da produção mundiais de mercadorias } \\
(Índice & $\mathbf{1 9 8 5}=$ & 100) & \\
\hline & 1950 & 1970 & 1990 & 1995 & 2003 \\
\hline Comércio mundial & 6 & 31 & 76 & 100 & 150 \\
Produção mundial & 17 & 50 & 94 & 100 & 124 \\
\hline Fonte: Cnuced. & 77 & & & \\
\hline
\end{tabular}

Nas novas condições de incremento da produção e circulação de mercadorias, exemplificadas por números na tabela, os dispositivos logísticos adquirem uma posição central já que articulam e integram - fisicamente, internamente e externamente - os espaços da produção e do consumo. As redes ultrapassam a dimensão de transporte típica da era industrial, pois integram uma mesma esfera de circulação e produção multilocalizada — montagem, transporte e distribuição final —, tornando a circulação produtiva. 


\section{As cidades portuárias na economia de circulação}

Em escala global, as redes produtivas dependem cada vez mais do transporte marítimo que é responsável pela maioria dos fluxos de bens materiais entre os continentes, associando-se também a outros tipos de modais. No passado, esse meio de transporte foi, durante muito tempo, caro e pouco seguro, constituindo um elo fraco dos sistemas de transporte. No entanto, nos últimos 20 anos, sua modernização permitiu reduzir o tempo de permanência dos navios no cais e aumentar a capacidade de carga dos mesmos, que são cada vez mais velozes e seguros, contribuindo assim na significativa diminuição do custo do frete marítimo. A modernização do transporte marítimo, bem como o desenvolvimento rápido do uso do contêiner, impôs uma transformação radical no sistema portuário mundial que tinha se tornado o elo fraco das grandes redes logísticas. Em conseqüência, nos anos 1980 e 1990, os países inseridos nos fluxos do comércio global empreenderam reformas portuárias que aplicaram algumas receitas institucionais e operacionais universais para conferir maior competitividade aos portos e à base produtiva nacional.

A reforma portuária brasileira combinada com o aumento dos investimentos no sistema portuário ilustra essa tendência: novas formas de regulação, descentralização e modernização das infra-estruturas e dos equipamentos, aparentemente, contribuíram para o aumento da eficiência das operações portuárias e para a diminuição do custo dos serviços que era, até então, um dos mais elevados do mundo. Até 1990, o sistema foi orientado e controlado pela Portobrás, quando esta foi extinta pelo governo federal, do então presidente Fernando Collor de Mello, e compreendia portos administrados pela mesma, portos administrados pelas companhias Docas, concessões estaduais, concessões particulares e terminais privados. Com a extinção da Portobrás, deflagrouse uma crise no setor, cujas negociações e articulações políticas redundaram na promulgação da Lei $\mathrm{n}^{\mathrm{0}}$ 8.630/93, que preconizou a modernização do setor. Para a sua formulação, aparentemente não foram consideradas as diferenças regionais e especificidades de cada porto, também não se observando a definição de uma política de orientação geral para os portos. Na verdade, essa lei neutralizou todas as anteriores, confirmando-se a definição de um órgão regulador do sistema apenas no início da década seguinte (2002), a Antaq — Agência Nacional de Transportes Aquaviários.

Entre os portos brasileiros, destaca-se o porto de Santos, o maior porto do Brasil, responsável pela movimentação de pouco mais de $27 \%$ da carga transportada em nosso país, com hegemonia reafirmada ao longo do tempo. Ele dispõe de uma rede de acessibilidade favorável, cuja cadeia produtiva inclui elementos dentro e fora das fronteiras brasileiras. No entanto, observa-se 
que os efeitos multiplicadores da atividade sobre a dinâmica da cidade aparentemente não condizem com a importância crescente do porto. Parte de tal situação é decorrente da radical transformação imposta ao setor, também sua desarticulação na formulação de uma agenda comum para a cidade ou mesmo região. As mudanças implementadas no porto com o Praps Programa de Arrendamento e Parcerias do Porto de Santos ficou restrito ao ambiente do cais.

No conjunto das transformações recentes, destacam-se três tendências, todas com impactos sobre as dinâmicas locais e formas relacionais porto-cidade. A primeira tendência para os portos, que se aplica aos portos de Santos e Rio de Janeiro, por exemplo, consiste na modernização do porto da era industrial. Segundo essa lógica, o porto tradicional caro, engessado do ponto de vista operacional e institucional, negativamente impactante sobre meio ambiente deve ser modernizado por intermédio de investimentos nas infra-estruturas e equipamentos portuários e uma reengenharia institucional, quebrando os monopólios. Essa opção, muito comum no Mercosul e no Brasil, segue as orientações básicas da reforma portuária e não questiona a natureza do porto. O que ela questiona é sua qualidade como instrumento de transporte, medida a partir de variáveis de desempenho operacional. Isso significa concretamente que, apesar da emergência de um novo paradigma produtivo, continuamos pensando o porto num contexto socioeconômico e político totalmente diferente.

Uma segunda alternativa reside na construção de megaportos voltados para a concentração e a redistribuição dos fluxos do comércio internacional para portos marítimos ou hinterlândias terrestres. Os portos de tipo hubs funcionam como instrumentos a serviço de multinacionais marítimas - os integradores globais e terrestres - que formam redes de circulação globais onde meganavios circulam em megarrotas marítimas e servem somente a megaportos estrategicamente localizados. A opção do porto-pivô foi, e continua sendo, extremamente popular nas instâncias que formulam as políticas públicas para o setor portuário. No Brasil, a maioria dos recursos destinados ao setor durante os anos 1990 foi aplicada na ampliação e na reestruturação dos portos de Pecém (Ceará), Suape (Pernambuco) e Sepetiba (Rio de Janeiro), todos idealizados como futuras portas de entrada sul-americanas dos fluxos globais. Tal tendência, além de não considerar que o Brasil representa somente cerca de $1 \%$ do comércio internacional, é pautada em projetos que apresentam várias limitações: os investimentos são consideráveis, as tecnologias de manuseio das cargas restringem a criação de empregos, as interações com o local de implantação são também limitadas, pois a função maior da plataforma portuária reside na sua capacidade de redistribuir imediatamente os fluxos que para ela convergem. Ou seja, o porto é um simples equipamento 
de transporte, inserido numa rede global e a serviço da lógica exclusivamente global das multinacionais, que beneficia pouco o lugar onde ele se localiza. Por isso, o hub é sempre apresentado como enclave desterritorializado que não contribui para o desenvolvimento da região onde foi implantado.

A terceira tendência consiste, ao contrário, na transformação do porto em instrumento a serviço do desenvolvimento local e/ou regional por meio de uma aproximação do porto e da cidade. A chamada "cidade portuária" prioriza, com efeito, a agregação de valor aos fluxos de cargas que transitam pelos seus portos. Trata-se, nesse caso, de uma leitura diferenciada do processo de globalização que, além do crescimento das trocas comerciais internacionais, caracteriza-se por uma transformação do modo de produzir que implica a agregação de um número crescente de atividades terciárias ao núcleo material do bem (Monié, 2003). Paralelamente, a regionalização dos modos de consumo exige uma "contextualização cultural" da elaboração final ou montagem de inúmeros produtos cuja forma de consumo varia muito de uma região para outra. A combinação dessas características oferece, assim, oportunidades de desenvolvimento às cidades-portos que apostam na "mercantilização" dos fluxos pelo estabelecimento de sinergias entre os recursos técnicos, oferecidos pelo porto e os serviços de transporte, e os recursos terciários oferecidos pelo tecido produtivo urbano.

Nos últimos anos, as cidades portuárias de parte da Europa e alguns portos em via de reestruturação como Gênova, Barcelona ou Valência, por exemplo, dotaram-se de parques logísticos que objetivam agregar valor aos fluxos das mercadorias destinadas aos mercados de consumo regionais. No Brasil, somente a cidade de Itajaí (Santa Catarina) parece ter optado por uma estratégia semelhante usando as oportunidades oferecidas pela municipalização do porto e a vitalidade da economia regional. Mesmo com o ineditismo da experiência, a mesma poderia ser referência para outros portos.

Para o conjunto das cidades brasileiras com portos, é fato que a aprovação da Lei no 8.630/93 e transformações derivadas da sua aplicação recolocaram a discussão dos portos no âmbito do desenvolvimento regional, em especial para as cidades brasileiras que já se ressentiam do afastamento dos seus portos. Parece ser consenso que o processo de afastamento dos portos em relação às cidades e regiões foi desencadeado já na década de 1950 e acentuado nas décadas subseqüentes, o que ocorreu em todas as cidades com portos, em diferentes países. Ao mesmo tempo, confirma-se que as alternativas e os instrumentos jurídicos disponíveis para a definição de um modelo de gestão portuária são vários, quando considerados os aspectos institucionais e administrativos. Hoje no Brasil tal diversidade se manifesta quando são constatadas as diferentes situações administrativas nos seus portos, confirmando-se situações 
de portos federalizados (Tubarão), portos municipalizados (Itajaí), portos estadualizados (Rio Grande), portos arrendados e explorados por empresas privadas (Santos), entre outros. Apesar de tais características, nem sempre se confirmam na gestão das cidades portuárias canais formais ou informais de interlocução com a gestão do porto.

\section{Alguns desafios para as políticas e gestão portuárias}

No Brasil "uma das conseqüências desta abertura abrupta e do discurso sobre a inserção competitiva do país na economia mundial foi a ênfase sobre a reorganização dos espaços produtivos" (Cocco e Silva, 2001:17), e a reforma do sistema portuário foi parte do conjunto de mudanças implementadas por sucessivos governos na década. Por meio de registros, identificou-se que à época predominavam argumentos relacionados à ausência de competitividade dos portos brasileiros, comprometimento e inadequação da infra-estrutura portuária, exaustão do modelo público de exploração portuária e esgotamento da capacidade de investimentos pelo Estado, excesso de centralização das decisões e, especialmente, pressões externas derivadas da inserção do país em uma economia mundial. Ao mesmo tempo, deve-se levar em conta que a participação dos investidores privados também incluiu certa seletividade de portos, sendo destinado para alguns deles quantias de recursos, para obras de infra-estrutura, melhorias gerais, bem como tecnologia necessária aos novos padrões internacionais de eficiência na prestação dos serviços. Criaram-se condições necessárias para a participação de agentes sociais privados no arrendamento de áreas, investimentos e operações portuárias. Entretanto, não se identifica a definição de uma política nacional de orientação geral, que também inclua traços e características locais. Aparentemente, a Lei no ${ }^{0}$ 8.630/93 foi o único documento norteador de todas as mudanças do sistema.

Nos primeiros anos da década, o setor foi caracterizado por intensas negociações em um ambiente de muita confusão, ausência de referências e de políticas, e a Lei no 8.630/93, a chamada Lei de Modernização dos Portos, foi promulgada como resposta à crise que se deflagrara. Até então, os serviços dos portos brasileiros se caracterizavam por um número expressivo de leis, visando a sua regulamentação: Decreto-Lei no 5.452, de 1943, que definiu os serviços de estiva e capatazia; Lei $\mathrm{n}^{\mathrm{O}} 5.400$ de 1944 , que definiu as instalações portuárias rudimentares; Lei no 4.860, de 1965, que definiu o regime de trabalho nos portos; Decreto-Lei $\mathrm{n}^{\mathrm{o}}$ 5, que visou modernizar o setor; e ainda, a Lei no 6.222 que criou a Empresa de Portos no Brasil S.A. - Portobrás. É oportuno ressaltar que com a promulgação da Lei $\mathrm{n}^{0} \mathbf{8 . 6 3 0 / 9 3}$ todas as anteriores foram suprimidas. 
As mudanças implementadas nos portos brasileiros não são uma experiência inédita. Ao contrário, elas foram antecedidas em outros portos do mundo: nos últimos 25 anos os portos de quase todos os países passaram por amplas e profundas reformas com o intuito de adequá-los à nova ordem estabelecida, em nível econômico e político internacional. Assim, as novas demandas econômicas oriundas da globalização contribuíram para uma revisão na atuação e estrutura dos portos em escala mundial. Entre as transformações, destaca-se, segundo Baird (1999:171) em artigo sobre a privatização dos portos na Grã-Bretanha, que

a primeira motivação seria a necessidade de erradicar deficiências nos portos, as que incluem também práticas de trabalho ultrapassadas que perpetuam a manutenção de um grande número de estivadores, o que era muito apropriado nos tempos dos navios convencionais, mas que dificilmente combina com as necessidades da era do contêiner.

Ao mesmo tempo, constatam-se trabalhos diversos que relatam os processos de privatização ou "modernização" dos portos em diferentes contextos e países, todos orientados pela busca da competitividade como forma de sobrevivência, ou melhor, como forma de otimizar lucros.

Vale observar que, no caso do Brasil, a ausência de uma verdadeira política portuária nacional conferiu às iniciativas, federais ou locais, um caráter fragmentado e, às vezes, bastante incoerente. Apesar dos resultados operacionais positivos, as inovações institucionais, mais especificamente em termos de governança portuária, são escassas, enquanto a problemática da relação entre o território urbano e o instrumento portuário não parece ter evoluído muito apesar do interesse recente do Ministério dos Transportes para com essa dimensão central da política pública portuária. Ou seja, na corrida entre os territórios que pretendem inserir-se no novo contexto produtivo global, as cidades-portos dispõem de atributos diferenciados e consideráveis, que permanecem freqüentemente ignorados pelas autoridades brasileiras, particularmente na definição de políticas direcionadas ao setor.

A globalização econômica, da qual se derivam ou associam as mudanças assinaladas acima, têm se caracterizado por um acentuado aumento dos fluxos de mercadorias que circulam por navios de um continente para outro, de um litoral a outro dos mares e oceanos e dos mares interiores, o que requer capacidade de organização e de promoção inovadora, assim como ações de planejamento mais articuladas. Como destaca Seassaro (1999:133), 
em relação à queda dos custos de transporte, a circulação de cargas é, com efeito, sempre menos sensível ao fator distância entre porto e lugar de origem ou destino terrestre das mercadorias. Inversamente, ela é cada vez mais sensível a diferentes fatores relativos, principalmente, ao tempo e ao custo de manipulação das cargas, assim como ao nível dos equipamentos de serviços complementares à movimentação.

O desafio maior, no entanto, reside na necessária invenção de uma nova governança portuária. A autoridade portuária deveria funcionar como uma instituição capaz de fomentar e estimular sinergias entre os agentes da economia marítima, portuária e urbana. Da mesma forma, a coordenação das autoridades portuárias em nível regional constituiria um avanço significativo para incentivar a cooperação das cidades-portos de uma mesma fachada marítima sudeste do Brasil, por exemplo - no intuito de resolver problemas comuns, realizando economias de escala: negociações com os agentes logísticos, questões ambientais, promoção da região portuária no exterior etc. A cooperação permitiria também valorizar complementaridades funcionais entre as cidades-portos. Essas novas escalas de ação das cidades portuárias são praticadas em algumas regiões do mundo, em particular no norte da Europa com a constituição de regiões portuárias no delta do rio Reno e em Hamburgo, onde os primeiros resultados parecem positivos do ponto de vista da conquista de novos mercados e da definição de novos arranjos logísticos.

O desafio da governança portuária supõe também uma definição mais clara e inovadora das atribuições da autoridade portuária a respeito de três questões fundamentais. Em primeiro lugar, a gestão fundiária nas áreas portuárias parece decisiva na hora em que se multiplicam os conflitos em torno do destino e uso dos armazéns ociosos, por exemplo. O problema da reconversão desses espaços não pode se limitar à apresentação do porto como um espaço ocioso e indesejável, que convém ser eliminado pela promoção de novos usos exclusivamente destinados ao lazer ou à especulação imobiliária. No Brasil, essas operações de tipo waterfronts se multiplicam há cerca de 15 anos segundo uma lógica bem específica, pois as cidades abandonam freqüentemente seu patrimônio fundiário e imobiliário sem participar das dinâmicas que seguem as reconversões funcionais, ao contrário de Nova York, por exemplo, onde as operações portuárias geram hoje menos benefícios do que a gestão fundiária.

Outro questionamento central é relativo à capacidade do porto de ampliar o espaço de atuação a partir das instalações portuárias para investir no campo dos dispositivos logísticos terrestres, desenvolvendo, assim, um papel mais ativo nas redes de valor agregado em escalas regional ou continental. A 
transformação da autoridade portuária em agente do planejamento e da gestão ambiental deveria também constituir uma prioridade. Além da ação local voltada para a resolução de problemas ambientais específicos, a aquisição de um saber-fazer em termos de gestão do meio ambiente costeiro urbano e regional pode representar uma competência lucrativa se for exportada para outros portos pela autoridade portuária ou por empresas especializadas.

Uma das mais significativas inovações da lei foi a criação do Conselho de Autoridade Portuária (CAP). Nesses conselhos, discute-se o futuro dos portos e são estabelecidas diretrizes para o seu desenvolvimento. Ele é um órgão normativo, de fomento e de deliberação sobre os assuntos relacionados a cada porto. O conselho é constituído por quatro blocos de membros titulares e seus suplentes, que representam o poder público (três representantes), os operadores portuários (quatro representantes), os trabalhadores portuários (quatro representantes) e os usuários dos serviços portuários e afins (cinco representantes). Cada bloco tem direito a um voto, cabendo ao representante do governo federal, como presidente do conselho, o voto de qualidade no caso de ocorrer um empate. Cabe ao conselho homologar horário de funcionamento do porto, opinar sobre propostas de orçamento, promover a otimização do uso das instalações portuárias e homologar os valores das tarifas, entre outros (Lei no 6.830/93). Na prática, a atuação dos conselhos, de modo geral, deixa a desejar, principalmente porque o mesmo atua em um ambiente ainda marcado por conflitos e indefinições. Ao mesmo tempo, deve-se considerar que, na prática, esses conselhos recebem uma delegação de poderes da União, a quem compete, privativamente, legislar sobre o regime dos portos, assumindo o papel antes desempenhado pelo Departamento Nacional de Portos e Vias Navegáveis e, posteriormente, pela Portobrás. No entanto, fica ainda reservada ao Ministério dos Transportes, por meio do atual Departamento de Portos e Hidrovias, a tarefa de fiscalizar as concessões, particularmente no que se refere ao cumprimento das cláusulas contratuais. O que ainda tem sido feito de forma muito tímida (Conti, 2000).

Passados mais de 10 anos da promulgação da lei, constata-se que os conflitos e desacertos entre os diferentes agentes do sistema persistem. Na verdade, os processos de privatização e descentralização não se limitam apenas à redefinição de atribuições, mas passam necessariamente pela transferência de poder envolvendo instâncias diversas, bem como indefinições e políticas. Ao mesmo tempo deve-se considerar que a estrutura organizacional do setor pretende integrar órgãos institucionalmente independentes, a saber: ministérios dos Transportes, da Fazenda, da Saúde e da Defesa (Marinha), Polícia Federal e secretarias estaduais. Em alguns casos, os portos de um mesmo estado estão ligados a mais de uma secretaria e, ainda, órgãos de um esta- 
do gerindo portos em outro estado (como, por exemplo, a Companhia Docas do Rio Grande do Norte). Além de todas essas instituições, deve-se considerar a atuação da Agência Reguladora - Antaq e de diversos órgãos dentro de cada porto, como também o grau de autonomia das outorgas. Ou seja, um cenário pouco favorável à definição de um modelo de gestão sinérgico, uma vez que não se observa uma atuação articulada, fazendo com que muitos conflitos sejam desencadeados ou mesmo assumam dimensões imaginárias.

\section{Considerações finais: inventar uma nova cultura portuária}

Conforme demonstramos no decorrer do artigo, a competição internacional no transporte de cargas marítimas, impulsionada pela globalização da economia, traz, na sua esteira, um processo de ruptura entre o modo de produção do porto antigo e as modalidades de gestão, operacionalização e funções de um porto moderno. Conforme reflexões de Seassaro (1999), o processo iniciado por meio de grandes movimentações de cargas, reforçado pela mundialização da produção, penetrou nas cidades portuárias de forma determinística e impositiva. Ao mesmo tempo, as novas perspectivas para a mobilização de cargas solicitam capacidades e organização estratégicas descoladas da realidade local, oficializando e alargando ainda mais a separação entre cidade e porto, instituindo a divisão simbólica entre o porto da cidade (urbano) e o porto eixo mundial (operacional). Uma outra leitura identifica os impactos positivos sobre a realidade local, decorrentes das operações logísticas necessárias às novas operações. A racionalização do espaço portuário, a favor da lógica nos transportes de cargas, é diferencial estratégico na disputa de mobilização das cargas e dos desdobramentos da rede de serviços decorrentes. Abre-se uma oportunidade favorável à integração porto-cidade ou, melhor ainda, para otimizar os negócios e atividades econômicas locais a partir do porto.

Pensar a cidade portuária no Brasil implica levar em consideração alguns obstáculos estruturantes. Em primeiro lugar, somos um país historicamente inserido de forma periférica na Divisão Internacional do Trabalho onde nossa margem de manobra revela-se, até hoje, relativamente estreita. Em conseqüência, o sistema portuário nacional é um sistema em parte comandado a partir de fora. Na era colonial, os portos funcionavam como nós de trânsito para os produtos primários destinados ao mercado europeu. Na virada do século XIX para o século XX, a construção de portos modernos foi ditada pelos imperativos dessa divisão do trabalho em escala mundial. No momento da industrialização do país, a expansão das plataformas portuárias quebra um pouco esse esquema, à medida que a retração do processo históri- 
co de globalização implica outras prioridades para os sistemas circulatórios, doravante centrados no território nacional em via de integração. Nos dias atuais, as transformações do sistema portuário são, a exemplo de um século atrás, em parte, impostas pelo ambiente mundial onde os países periféricos constrangidos pelos imperativos de pagamento do serviço da dívida externa especializam sua agenda de exportações, valorizando alguns produtos primários como a soja ou o ferro, no caso brasileiro.

Nesse contexto, as pressões exercidas pelas grandes tradings de commodities de um lado e os armadores e operadores do transporte marítimo do outro reforçam o sentimento de dependência em relação a agentes nacionais e internacionais que defendem, em primeiro lugar, seus interesses específicos de grupo, suas corporações. Essa dinâmica é particularmente negativa, pois se sobrepõe aparentemente em um sentimento histórico de rejeição relativa dos portos, em países periféricos, onde os mesmos funcionaram historicamente como portas de saída das riquezas nacionais (açúcar, ouro) e portas de entrada de todos os elementos que simbolizam uma inserção dependente no sistema mundial (tráfego de escravos, pirataria), em tempos coloniais, já apontado por Darcy Ribeiro (Cocco e Silva, 1999).

Outro constrangimento que deve ser considerado reside no fato de que o Brasil ocupa uma posição marginal nos circuitos do comércio internacional, sendo responsável por cerca de $1 \%$ dos fluxos globais. O fato dos fluxos de mercadorias se concentrarem entre os pólos da tríade - América do Norte, União Européia, Ásia do leste e do sudeste - posiciona os portos do hemisfério Sul nos eixos secundários do sistema marítimo internacional. Nessas condições, a opção do governo federal e de várias cidades-portos brasileiros na construção de megainstalações de tipo hub de primeira categoria, aparentemente se tornou uma proposta pouco realista. Mas, tanto no âmbito do aparelho de Estado quanto na sociedade, a sedução exercida pelos grandes empreendimentos infra-estruturais permanece um constrangimento para pensar a cidade-porto no momento em que o dinamismo produtivo depende cada vez mais de atividades incluindo muito trabalho imaterial (Negri, 2003).

Enfim, um último aspecto merece ser destacado: as dificuldades metodológicas no cálculo preciso do valor agregado portuário na interface mar-terra. A ausência de dados elucidativos dificulta certamente a difusão da idéia postulando uma necessária aproximação do porto e da cidade como vetor possível de desenvolvimento pela mercantilização dos fluxos do comércio internacional. Nesse contexto, inventar uma cultura urbano-portuária, onde cidade e porto são mais complementares do que antagônicos, representa então um desafio central para a sociedade, os atores econômicos e as diversas esferas do poder político. 
Consideramos ser de fundamental importância, para o processo de gestão portuária, a implantação de um sistema de acompanhamento permanente do desempenho operacional, dos preços dos serviços portuários, proporcionando, assim, a disponibilidade de dados e informações consistentes aos usuários. Ao mesmo tempo, parece ser oportuna a definição de instrumentos de acompanhamento e controle das ações implementadas, bem como políticas compensatórias, em especial, as destinadas ao redirecionamento da força de trabalho portuária e sua reinserção no mercado de trabalho, bem como ações integradoras e parcerias com os novos agentes privados atuantes no porto. Na verdade, trata-se de um processo ainda em construção, que poderá resultar em um novo modelo de gestão que concilie os interesses privados ao ambiente do porto e interesses local-regionais.

Entre as pendências identificadas, destaca-se uma primeira, de ordem geral e presente no conjunto dos portos brasileiros, que diz respeito à limitada implementação da Lei no 8.639/93 e todas as regulamentações decorrentes. Em alguns portos, no caso do porto de Santos, por exemplo, constata-se que o processo de privatização se deu em um ambiente de aparente desarticulação, priorizando-se apenas a privatização e a desregulamentação no trabalho, em detrimento da atuação do Conselho de Autoridade Portuária e da própria aceitação da nova autoridade portuária (até 2001 os operadores portuários recusavam-se em delegar à Codesp tal função). Por outro lado, a própria Codesp, seus funcionários, sua cultura, de certa maneira, também "relutam" em aceitar a nova função, confirmando-se uma situação híbrida, com elementos de operadora portuária e de autoridade. Ou seja, um conjunto de práticas que limitam a disseminação de uma cultura portuária.

A discussão acerca das cidades portuárias e a formação ou fortalecimento das relações que visem uma melhor integração porto-cidade, evidenciando-se os benefícios decorrentes da atividade portuária, não parece tarefa fácil. Na verdade, ela não se restringe apenas ao ambiente dos negócios, mas requer a inclusão de elementos históricos, culturais e sociais, já que se trata de uma relação que ainda comporta estigmas, perdas, redefinições de funções, conflitos e interesses diversos, e isso nem sempre está presente nas negociações de mercado. Portanto, trata-se de um processo ainda em construção, que poderá resultar em um novo modelo de gestão portuária, compatível com a diversidade do novo porto, fruto de uma interação qualitativamente diferenciada entre os agentes sociais (operadores, trabalhadores, usuários, arrendatários) e institucionais (autoridade portuária, Antaq, governos representados) e o CAP parece se constituir em fórum privilegiado, ao mesmo tempo em que poderá favorecer a disseminação de uma cultura portuária. 
Finalmente, aos aspectos abordados aqui, acrescentamos a possível aceitação de um "paradigma da cooperação", caracterizado pelo estabelecimento e desenvolvimento do diálogo e interação entre os agentes sociais do processo, como elemento básico para definição de uma nova cultura portuária. Na perspectiva do mesmo, as organizações humanas são priorizadas, em contraposição ao paradigma da competição e seus efeitos indesejáveis a partir da agressividade e da prioridade concedida apenas aos sistemas técnicos. A adoção desse paradigma também poderá se constituir na base para se pensar, e trabalhar conceitualmente, o estabelecimento de uma nova dinâmica entre o porto e a cidade, e conseqüente fortalecimento do sistema, que também deverá ser integrado à dinâmica mais geral da cidade e da região.

\section{Referências bibliográficas}

BAIRD, Alfred J. A privatização dos portos na Grã-Bretanha. In: COCCO, Giuseppe; SILVA, Gerardo (Orgs.). Cidades e portos: os espaços da globalização. Rio de Janeiro: DP\&A, 1999.

BAUDOUIN, Thierry. A cidade portuária na mundialização. In: COCCO, G.; SILVA, G. (Orgs.). Cidades e portos: os espaços da globalização. Rio de Janeiro: DP\&A, 1999.

BNDES. Arrendamentos portuários. Cadernos de Infra-estrutura, n. 16. Rio de Janeiro: BNDES, 2001.

BRASIL. Decreto-Lei $n^{0}$ 8.930, de 25 de fevereiro de 1993.

- Ministério dos Transportes. Geipot (Empresa de Planejamento de Transportes). A reforma portuária brasileira. Brasília, set. 2001.

CASTELLS, Manuel. A sociedade em rede. São Paulo: Paz e Terra, 1999.

COCCO, G.; SILVA, G. (Orgs.). Cidades e portos: os espaços da globalização. Rio de Janeiro: DP\&A, 1999.

COLLIN, Michéle. A evolução do estatuto dos portos na Europa. In: COCCO, G.; SILVA, G. (Orgs.). Cidades e portos: os espaços da globalização. Rio de Janeiro: DP\&A, 1999.

—. Mobilizações produtivas na cidade portuária. In: MONIÉ, Frédéric; SILVA, Gerardo (Orgs.). A mobilização produtiva dos territórios: instituições e logística do desenvolvimento local. Rio de Janeiro: DP\&A, 2003a.

Ville portuaire, acteur du développement durable. Paris, França: Maritimes, L'Harmattan, 2003b. 
CONTI, José Mauro Otero. A modernização dos portos no Brasil. Rio de Janeiro: Escola Superior de Guerra, 2000.

CONTOIS, C.; SLACK, B. Innover l'autorité portuaire au 21eme siécle: un nouvel agenda de gouvernance. Les Cahiers Scientifiques du Transport, Montreal, Canadá, n. 44, p. 11-24, 2003.

FARIA, S. Transporte aquaviário e a modernização dos portos. São Paulo: Aduaneiras, 1998.

FERREIRA, Vítor Matias; INDOVINA, Francesco (Orgs.). A cidade da Expo' 98: uma reconversão da frente ribeirinha de Lisboa? Lisboa: Bizâncio, 1999.

FERREIRA, Vítor Matias et al. Lisboa, a metrópole e o rio. Lisboa: Bizâncio, 1997.

GODOY, Amália Maria Golberg. Reestruturação produtiva do mercado de trabalho em Paranaguá. Revista Paranaense de Desenvolvimento, Curitiba, n. 99, p. 5-25, jul./dez. 2000.

HARVEY, David. Condição pós-moderna. São Paulo: Loyola, 1989.

LACERDA, S. Magalhães. Navegação e portos no transporte de contêineres. Revista do $B N D E S$, v. 11, n. 22, p. 215-243, 2004.

MONIÉ, Frédéric; SILVA, Gerardo (Orgs.). A mobilização produtiva dos territórios. Instituições e logística do desenvolvimento local. Rio de Janeiro, DP\&A, 2003.

NEGRI, A.; Lazzarato, M. Trabalho imaterial. Rio de Janeiro: DP\&A, 2003.

PINHEIRO, Ivan Antonio; MOTTA, Paulo Delayn. A condição de autarquia especial das agências reguladoras e das agências executivas e as expectativas sobre a qualidade da sua gestão. RAP, Rio de Janeiro, v. 36, n. 3, p. 459-483, maio/jun. 2002.

ROSA, Ana Miriam dos Santos. Aspectos do desenvolvimento dos complexos portuários de Santos e de Roterdã: uma contribuição à modernização do maior porto brasileiro. 1996. Tese (Doutorado) — São Paulo.

SALES, Pedro Manuel Rivaben. Santos - a relação entre porto e a cidade e sua (re)valorização no território macrometropolitano de São Paulo. 1999. Tese (Doutorado) — Faculdade de Arquitetura e Urbanismo da Universidade de São Paulo — USP, São Paulo.

SEASSARO, Loredana. O sistema portuário italiano: privatização, operadores transnacionais e recomposição da relação porto-cidade. In: COCCO, G.; SILVA, G. (Orgs.). Cidades e portos: os espaços da globalização. Rio de Janeiro: DP\&A, 1999.

STORPER, Mi. Territories, flows and hierarchies in the global economy. In: BARNES et al. Reading Economic Geography Oxford, Blackwell, 2004.

VELTZ, P. Des lieux et des liens. Politiques du territoire à l'heure de la mondialisation. Paris: Editions de l'Áube, 2002. 


\section{Web sites}

$<$ www.portodesantos.com.br $>$.

$<$ www.geipot.gov.br>.

$<$ www.pr.gov.br/portos $>$.

$<$ www.portosenavios.inf.br $>$.

$<$ www.portosrio.gov.br $>$.

$<$ www.ogmo-santos.com.br>.

$<$ www.transportes.gov.br $>$.

$<$ www.portoitajai.com.br $>$.

$<$ www.portoriogrande.com.br $>$.

$<$ www.paranagua.com.br>. 